\title{
Schistosomiasis and hepatopulmonary syndrome: the role of concomitant liver cirrhosis
}

\author{
Liana Gonçalves-Macedor ${ }^{1}+$, Edmundo Pessoa Lopes ${ }^{2}$, Ana Lucia Coutinho Domingues², \\ Brivaldo Markman-Filho ${ }^{3}$, Vitor Gomes Mota ${ }^{3}$, Carlos Feitosa Luna ${ }^{4}$ \\ Universidade Federal de Pernambuco, Programa de Pós-Graduação em Medicina Tropical, Recife, PE, Brasil \\ ${ }^{2}$ Universidade Federal de Pernambuco, Departamento de Medicina Clínica, Serviço de Gastroenterologia e Hepatologia, Recife, PE, Brasil \\ ${ }^{3}$ Universidade Federal de Pernambuco, Departamento de Medicina Clínica, Serviço de Cardiologia e Ecocardiografia, Recife, PE, Brasil \\ ${ }^{4}$ Fundação Oswaldo Cruz-Fiocruz, Laboratório de Métodos Quantitativos em Saúde, Recife, PE, Brasil
}

BACKGROUND Hepatopulmonary syndrome (HPS) is defined as an oxygenation defect induced by intrapulmonary vasodilation in patients with liver disease or portal hypertension. It is investigated in patients with liver cirrhosis and less frequently in those with portal hypertension without liver cirrhosis, as may occur in hepatosplenic schistosomiasis (HSS).

OBJECTIVES To investigate the prevalence of HPS in patients with HSS, and to determine whether the occurrence of HPS is influenced by concomitant cirrhosis.

METHODS We evaluated patients with HSS with or without concomitant liver cirrhosis. All patients underwent laboratory testing, ultrasound, endoscopy, contrast echocardiography, and arterial blood gas analysis.

FINDINGS Of the 121 patients with HSS, 64 were also diagnosed with liver cirrhosis. HPS was diagnosed in 42 patients (35\%) and was more frequent among patients with concomitant liver cirrhosis than in those without cirrhosis (42\% vs. 26\%), but the difference was not significant $(\mathrm{p}=0.069)$. HPS was more common in those with spider naevi, Child-Pugh classes $\mathrm{B}$ or $\mathrm{C}$ and high model for end stage liver disease (MELD) scores $(\mathrm{p}<0.05$ each).

MAIN CONCLUSIONS The prevalence of HPS was 35\% in this study. The occurrence of liver cirrhosis concomitantly with HSS may have influenced the frequency of patients presenting with HPS.

Key words: neglected diseases - portal hypertension - oesophageal and gastric varices - ultrasound - schistosomiasis - hepatopulmonary syndrome

Hepatopulmonary syndrome (HPS) is defined as a clinical triad characterised by an oxygenation defect induced by the presence of pulmonary vasodilation observed in patients with liver disease or portal hypertension (Machicao \& Fallon 2012). There are no pathognomonic signs or symptoms of HPS, although dyspnoea, platypnoea, peripheral cyanosis, digital clubbing, and spider naevi may be observed (Rodríguez-Roisin et al. 2004). While the pathophysiology of HPS has not been fully clarified, it is known that in portal hypertension, there is an increase in substances produced by the liver that could act on the lungs, thereby promoting vasodilation, with a consequent increase in the arterial alveolar oxygen gradient and hypoxemia (Machicao \& Fallon 2012).

Portal hypertension may also lead to another vascular pulmonary complication, pulmonary arterial hypertension (Simonneau et al. 2013). Its pathophysiology is opposite to HPS, being pulmonary vasoconstriction and elevated pulmonary vascular resistance (RodríguezRoisin et al. 2004). Unlike HPS, pulmonary arterial hy-

\footnotetext{
doi: 10.1590/0074-02760160383

+ Corresponding author: lianagmacedo@gmail.com

Received 22 August 2016

Accepted 13 March 2017
}

pertension may be idiopathic or secondary to various conditions besides portal hypertension (Simonneau et al. 2013). The diagnosis of pulmonary arterial hypertension is confirmed by haemodynamic studies, and occurs in $2 \%$ to $6 \%$ of patients with portal hypertension, including schistosomiasis (Lapa et al. 2009, Simonneau et al. 2013). The prevalence of HPS is lower in patients with non-cirrhotic portal hypertension ( $8 \%$ to $9.7 \%$ ), than in those with cirrhosis ( $15 \%$ to $17.5 \%$ ), in whom the presence of HPS is related to a poor prognosis (De et al. 2000, Martínez et al. 2001, Kaymakoglu et al. 2003, Fallon et al. 2008, Ferreira et al. 2008).

In Brazil, a leading cause of non-cirrhotic portal hypertension is hepatosplenic schistosomiasis (HSS), which results from chronic infection with Schistosoma mansoni (Gryseels 2012, Lambertucci 2014). When patients with HSS develop cirrhosis due to infection with hepatitis $\mathrm{B}$ virus (HBV) or hepatitis $\mathrm{C}$ virus (HCV), chronic alcohol consumption, or other causes, their prognosis worsens as a result of greater impairment of liver function, with a possibility of the involvement of other organs or systems (Bosch et al. 2008, Barsoum et al. 2013, Van-Lume et al. 2013).

In HSS patients, HPS is rarely reported, either because its prognostic implications are not well known, or because HSS patients typically show only mild impairment of their liver function and are therefore not candidates for liver transplantation (Ferreira et al. 2009, Lambertucci 2014). In addition, it has yet to be determined 
whether concomitant cirrhosis in HSS patients plays a role in the development of HPS. The objective of this study was to undertake a prospective investigation into the prevalence of HPS in patients with HSS, and to determine whether the occurrence of HPS is influenced by concomitant hepatic cirrhosis.

\section{SUBJECTS AND METHODS}

This was a prospective, cross-sectional, hospitalbased study, in which all patients diagnosed with HSS and oesophageal varices, with or without concomitant liver cirrhosis, between April 2010 and December 2012 were eligible for inclusion in this study protocol, i.e., screening for HPS. Splenectomised patients and those who had consumed alcohol in the past six months, presented with severe cardiac disease or severe restrictive or obstructive lung disorder observed on spirometry or were receiving antiviral therapy for hepatitis, were excluded.

Each patient was evaluated individually by the same observer. On this occasion, information regarding the period and place of exposure to S. mansoni was obtained through the patient's origin and previous addresses, previous treatment with praziquantel (PZQ), previous blood transfusion, alcohol consumption and laboratory diagnosis of infection with HBV and HCV.

The diagnosis of HSS was based on a history of contact with water in an area endemic for S. mansoni, together with ultrasound findings of periportal hepatic fibrosis (Symmers' fibrosis) and splenomegaly (Richter et al. 2001). The additional diagnosis of liver cirrhosis in patients with HSS was based on clinical findings, liver function test results, and ultrasound findings consistent with a diagnosis of liver cirrhosis (liver surface nodularity, evaluated by ultrasound at the left liver lobe) as well as on liver histology when a biopsy was performed (Bosch et al. 2008, Berzigotti et al. 2010). The severity of liver disease was assessed by Child-Pugh criteria (hepatic encephalopathy, ascites, prothrombin time or the international normalised ratio and serum levels of albumin and bilirubin) and the model for end-stage liver disease (MELD) score (Child and Turcotte 1964, Kamath et al. 2001). The severity of previous lung disease was assessed by performing forced spirometry in all patients (Micro Kit; Cosmed, Rome, Italy), and predicted values were based on the reference values for Brazil (Pereira et al. 2007).

The diagnosis of HPS was based on a widened alveolar-arterial partial pressure oxygen gradient $\left(\mathrm{AaPO}_{2}\right)(\geq$ $15 \mathrm{mmHg}$ or $\geq 20 \mathrm{mmHg}$ for individuals over 64 years of age), with or without arterial hypoxemia $\left(\mathrm{PaO}_{2}<80\right.$ $\mathrm{mmHg}$ ), and intrapulmonary vascular dilatation (IPVD), as diagnosed by transthoracic contrast-enhanced echocardiography (Rodríguez-Roisin et al. 2004). Patients without HPS were included as controls.

Procedures for diagnosing HPS: transthoracic contrast-enhanced echocardiography - Echocardiography was performed with an ultrasound system (HDI 1500; Philips Medical Systems, Eindhoven, the Netherlands). With the patient in the lateral decubitus position, we punctured a vein in the arm and inserted a three-way catheter for contrast injection ( $0.9 \%$ saline). The test was considered positive for IPVD if opacification of the left atrium was observed between the fourth and the sixth cardiac cycles, counted from the opacification of the right atrium in the absence of intracardiac communications (Vedrinne et al. 1997).

Arterial blood gas analysis - Arterial blood samples were obtained through radial artery puncture while the patient was seated, at rest, and breathing ambient air at sea level. Each sample was immediately analysed (GEM 3000; Instrumentation Laboratory, Bedford, MA, USA) to determine the $\mathrm{pH}, \mathrm{PaO}_{2}$ and arterial carbon dioxide tension $\left(\mathrm{PaCO}_{2}\right)$ values. The $\mathrm{AaPO}_{2}$ value was calculated according to the alveolar gas equation (Rodríguez-Roisin et al. 2004).

Statistical analysis - Statistical analysis was performed using the Statistical Package for the Social Sciences, version 8.0 (SPSS Inc., Chicago, IL, USA). Continuous variables are expressed as mean \pm standard deviation and categorical variables, as absolute and relative frequencies. As measures of association, we used the Student's t-test for continuous variables and the $X^{2}$ test, together with Fisher's exact test, when indicated, for categorical variables. The cases without HPS were used as controls. Values of $\mathrm{p}<0.05$ were considered statistically significant.

Ethics - The study was approved by the Research Ethics Committee of the Federal University of Pernambuco Health Sciences Centre (Protocol no. 396/2010). All participating patients provided written informed consent.

\section{RESULTS}

Of the 175 patients diagnosed with HSS and oesophageal varices, 121 completed the study protocol. The study included 68 males (56.2\%), and the mean age was $56 \pm 12$ years. All patients had been exposed to water contaminated by S. mansoni; 62 (51.2\%) presented a history of treatment with PZQ, and $64(52.8 \%)$ presented with the additional diagnosis of cirrhosis, the most common cause of which was alcohol consumption (43.8\%) followed by HCV infection (28.1\%) (Table I).

Forty-two patients (35\%) were diagnosed with HPS. The prevalence of HPS was higher among patients with cirrhosis than among those without cirrhosis ( $42 \%$ vs. $26 \%$, respectively), but the difference was not significant $(p=0.069)$. The prevalence of HPS was also higher among patients with spider naevi, those classified as Child-Pugh class $\mathrm{B}$ or $\mathrm{C}$, and those with high MELD scores $(\mathrm{p}<0.05$ each) (Table II).

Regarding the spirometry parameters and arterial blood gas analysis parameters, there were no significant differences between the patients with and without HPS, with the exception of the $\mathrm{AaPO}_{2}$ value, which was higher in patients with HPS $(p=0.037)$ (Table II).

Regarding abdominal ultrasound parameters (Symmers' fibrosis pattern, longitudinal diameter of the spleen and transverse diameters of the portal and splenic veins) and endoscopy parameters (calibre of the oesophageal varices and the presence of portal hypertensive gastropathy), we observed no significant differences between patients with and without HPS (Table III). 
TABLE I

Age, gender and epidemiological characteristics of 121 patients with hepatosplenic schistosomiasis (HSS)

\begin{tabular}{|c|c|c|}
\hline & $\mathrm{N}$ & $(\%)$ \\
\hline Age (mean \pm standard deviation) & $55,6 \pm 11,50$ & \\
\hline \multicolumn{3}{|l|}{ Gender } \\
\hline Male & 68 & 56.2 \\
\hline Female & 53 & 43.8 \\
\hline \multicolumn{3}{|c|}{ Exposure to Schistosoma mansoni contaminated water } \\
\hline No & 0 & 0.0 \\
\hline Yes & 121 & 100.0 \\
\hline \multicolumn{3}{|l|}{ Previous treatment for schistosomiasis } \\
\hline No & 59 & 48.8 \\
\hline Yes & 62 & 51.2 \\
\hline \multicolumn{3}{|l|}{ Hemotransfusion history } \\
\hline No & 74 & 61.2 \\
\hline Yes & 47 & 38.8 \\
\hline \multicolumn{3}{|l|}{ Cause of cirrhosi* } \\
\hline Alcohol & 28 & 43.8 \\
\hline $\mathrm{HCV}$ & 18 & 28.1 \\
\hline HBV-Alcohol & 7 & 10.9 \\
\hline $\mathrm{HBV}$ & 6 & 9.4 \\
\hline HCV-Alcohol & 1 & 1.6 \\
\hline HCV-HBV & 1 & 1.6 \\
\hline Cirrhosis through other causes & 3 & 4.6 \\
\hline
\end{tabular}

*: 64 patients with HSS with concomitant cirrhosis; HCV: hepatitis C virus; HBV: hepatitis B virus.

\section{DISCUSSION}

The main finding of this study was the high prevalence of HPS in patients with HSS, than in patient with non-cirrhotic portal hypertension and those with cirrhotic portal hypertension on liver transplant waiting lists, as that reported in other studies evaluating the same diagnostic arterial blood gas parameters (De et al. 2000, Martínez et al. 2001, Kaymakoglu et al. 2003, Ferreira et al. 2008). The prevalence of HPS observed in the present study was also higher than that reported in a study that examined patients with chronic forms of infection by $S$. mansoni (10\% HPS prevalence) without mentioning the presence of oesophageal varices (Ferreira et al. 2009).

Although non-cirrhotic portal hypertension is associated with the development of HPS (Rodríguez-Roisin et al. 2004), it remains unclear whether the presence of HPS correlates with the highest levels of portal hypertension. In our study, parameters such as large-calibre oesophageal varices, portal hypertension gastropathy, very advanced periportal fibrosis, a greater longitudinal diameter of the spleen, portal collaterals and dilatation of portal vessels, usually present in patients with higher levels of portal hypertension (de Franchis \& Dell'Era 2007, Andrade 2009, Berzigotti et al. 2013), were not significantly more frequent in patients with HPS. In fact, we observed that the prevalence of HPS was significantly higher among patients with spider naevi and high Child-Pugh and MELD scores, parameters that indicate the most severe liver function impairment. Thus, it is interesting to note that the incidence of HPS was higher in patients with concomitant cirrhosis than in those with HSS but without cirrhosis ( $42 \%$ vs. $26 \%$ ), although there was only a trend of statistical significance.

These findings may suggest that, for patients in the present study, impaired hepatic function had a greater influence than the possible higher levels of portal pressure, over the occurrence of HPS. It may also be that the ultrasound and endoscopy changes secondary to portal hypertension, used herein as indirect parameters of portal hypertension, were insufficient to demonstrate any difference between patients with and without HPS. Hence, because the portal pressure was not measured, this point remains unclarified, and therefore constitutes one of the limitations of this study. However, the measurement of the hepatic venous pressure gradient, a method used to obtain the portal pressure level in patients with cirrhosis, does not properly assess the pressure in the venous portal system in patients with HSS because these patients present pre-sinusoidal portal hypertension (Coutinho 1968, Merkel \& Montagnese 2011).

Another interesting finding of the present study was that the $\mathrm{AaPO}_{2}$ value was also elevated in patients without HPS. The involvement of lung tissue has been reported in patients with schistosomiasis, which was also described in an experimental study involving mice chronically infected with S. mansoni (de Faria et al. 1959, Fairfax et al. 2012). It should be noted that although the 
TABLE II

Clinical findings, arterial blood gas analysis and intrapulmonary vascular dilatation in hepatosplenic schistosomiasis (HSS) patients with and without hepatopulmonary syndrome (HPS)

\begin{tabular}{|c|c|c|c|}
\hline & $\begin{array}{c}\text { HPS } \\
(n=42)\end{array}$ & $\begin{array}{c}\text { Non-HPS } \\
(\mathrm{n}=79)\end{array}$ & p-value \\
\hline Age (years), mean \pm SD & $52.79 \pm 13.22$ & $57.05 \pm 10.25$ & 0.055 \\
\hline \multicolumn{4}{|l|}{ Gender, n (\%) } \\
\hline Male & $25(60)$ & $43(54)$ & \\
\hline Female & $17(40)$ & $36(46)$ & 0.591 \\
\hline \multicolumn{4}{|l|}{ Clinical findings } \\
\hline \multicolumn{4}{|l|}{ Liver disease, $\mathrm{n}(\%)$} \\
\hline HSS & $15(36)$ & $42(53)$ & \\
\hline HSS with cirrhosis & $27(64)$ & $37(47)$ & 0.069 \\
\hline Spider naevi, n (\%) & $13(31)$ & $11(14)$ & 0.029 \\
\hline \multicolumn{4}{|l|}{ Child-Pugh class, n (\%) } \\
\hline A & $23(55)$ & $64(81)$ & \\
\hline $\mathrm{B} / \mathrm{C}$ & $19(45)$ & $15(19)$ & 0.003 \\
\hline MELD score, mean \pm SD & $12.31 \pm 3.68$ & $10.46 \pm 3.22$ & 0.007 \\
\hline \multicolumn{4}{|l|}{ Spirometry } \\
\hline FVC (\% predicted) & $76.90 \pm 10.91$ & $73.73 \pm 14.10$ & 0.173 \\
\hline $\mathrm{FEV}_{1}(\%$ predicted $)$ & $81.50 \pm 10.80$ & $78.20 \pm 13.99$ & 0.153 \\
\hline $\mathrm{FEV}_{1} / \mathrm{FVC}$ & $0.87 \pm 0.07$ & $0.86 \pm 0.06$ & 0.956 \\
\hline \multicolumn{4}{|l|}{ Arterial blood gas analysis } \\
\hline $\mathrm{PaO}_{2}$, mean $\pm \mathrm{SD}$ & $77.60 \pm 9.78$ & $80.41 \pm 11.35$ & 0.177 \\
\hline $\mathrm{PaCO}_{2}$, mean $\pm \mathrm{SD}$ & $35.14 \pm 3.94$ & $36.67 \pm 4.06$ & 0.052 \\
\hline $\mathrm{AaPO}_{2}{ }^{*}$, mean $\pm \mathrm{SD}$ & $28.14 \pm 9.51$ & $23.42 \pm 12.47$ & 0.037 \\
\hline IPVD $^{*}, \mathrm{n}(\%)$ & $42(100)$ & $9(11)$ & $<0.001$ \\
\hline
\end{tabular}

IPVD: intrapulmonary vascular dilatations; MELD: model for end-stage liver disease; SD: standard deviation; *: diagnostic parameter for hepatopulmonary syndrome.

TABLE III

Ultrasound and endoscopic findings in hepatosplenic schistosomiasis (HSS) patients with and without hepatopulmonary syndrome (HPS)

\begin{tabular}{|c|c|c|c|}
\hline & $\begin{array}{c}\text { HPS } \\
(n=42)\end{array}$ & $\begin{array}{c}\text { Non-HPS } \\
(\mathrm{n}=79)\end{array}$ & p-value \\
\hline \multicolumn{4}{|l|}{ Ultrasound findings } \\
\hline \multicolumn{4}{|l|}{ Symmers' Fibrosis Pattern, n (\%) } \\
\hline $\mathrm{D}$ & $25(60)$ & $34(43)$ & \\
\hline $\mathrm{E} / \mathrm{F}$ & $17(40)$ & $45(57)$ & 0.086 \\
\hline Spleen, longitudinal diameter ${ }^{*}$ & $15.01 \pm 2.24$ & $15.81 \pm 2.57$ & 0.093 \\
\hline Portal vein, transverse diameter ${ }^{*}$ & $1.17 \pm 0.31$ & $1.24 \pm 0.31$ & 0.301 \\
\hline Splenic vein, transverse diameter ${ }^{*}$ & $0.95 \pm 0.27$ & $0.97 \pm 0.31$ & 0.790 \\
\hline \multicolumn{4}{|l|}{ Endoscopic findings } \\
\hline \multicolumn{4}{|l|}{ Esophageal varices, n (\%) } \\
\hline Mild & $24(57)$ & $45(57)$ & \\
\hline Medium/Large & $18(43)$ & $34(43)$ & 0.985 \\
\hline Portal hypertensive gastropathy, n (\%) & $36(86)$ & $58(73)$ & 0.128 \\
\hline
\end{tabular}

*: mean \pm standard deviation. 
involvement of lung tissue was not a focus of our study, this might have contributed to the widened $\mathrm{AaPO}_{2}$, irrespective of the presence of IPVD, resulting in an overestimation of the frequency of HPS.

In conclusion, the concomitant occurrence of hepatic cirrhosis with HSS may have influenced the finding of a higher frequency of HPS in this study. Given that HPS interferes negatively in the prognosis of patients with cirrhosis, its investigation could be performed during the routine care of patients with HSS and oesophageal varices, especially in those patients with concomitant cirrhosis. The diagnostic evaluation of HPS in patients with schistosomiasis may require further evaluation of the additional involvement of interstitial lung disease in these patients. Further studies assessing the prognostic significance of HPS in patients with schistosomiasis would be of great interest to clinical practice.

\section{AUTHORS' CONTRIBUTION}

LGM, EPL and ALCD - Conception and design of the study; LGM, EPL, ALCD, BMF and VGM - acquisition of the data; LGM and CFL - analysis of the data; LGM, EPL and CFL - interpretation of the data and drafting of the article; LGM, EPL, ALCD and BMF - critical revision for important intellectual content.

\section{REFERENCES}

Andrade ZA. Schistosomiasis and liver fibrosis. Parasite Immunol. 2009; 31(11): 656-63.

Barsoum RS, Esmat G, El-Baz T. Human schistosomiasis: clinical perspective: review. J Adv Res. 2013; 4(5): 433-44.

Berzigotti A, Abraldes JG, Tandon P, Erice E, Gilabert R, GarcíaPagan JC, et al. Ultrasonographic evaluation of liver surface and transient elastography in clinically doubtful cirrhosis. J Hepatol. 2010; 52(6): 846-53.

Berzigotti A, Seijo S, Arena U, Abraldes JG, Vizzutti F, García-Pagán JC, et al. Elastography, spleen size, and platelet count identify portal hypertension in patients with compensated cirrhosis. Gastroenterology. 2013; 144(1): 102-11.e1.

Bosch J, Berzigotti A, Garcia-Pagan JC, Abraldes JG. The management of portal hypertension: rational basis, available treatments and future options. J Hepatol. 2008; 48(Suppl. 1): S68-92.

Child CG, Turcotte JG. Surgery and portal hypertension. Major Probl Clin Surg. 1964; 1: 1-85.

Coutinho A. Hemodynamic studies of portal hypertension in schistosomiasis. Am J Med. 1968; 44(4): 547-56.

De BK, Sen S, Sanyal R. Hepatopulmonary syndrome in noncirrhotic portal hypertension. Ann Intern Med. 2000; 132(11): 924.

de Faria JL, Barbas JV, Fujioka T, Lion MF, Silva UA, Decourt LV. Pulmonary schistosomatic arteriovenous fistulas producing a new cyanotic syndrome in Manson's schistosomiasis. Am Heart J. 1959; 58: 556-67.

de Franchis R, Dell'Era A. Non-invasive diagnosis of cirrhosis and the natural history of its complications. Best Pract Res Clin Gastroenterol. 2007; 21(1): 3-18.

Fairfax KC, Amiel E, King IL, Freitas TC, Mohrs M, Pearce EJ. IL10R blockade during chronic schistosomiasis mansoni results in the loss of B cells from the liver and the development of severe pulmonary disease. PLoS Pathog. 2012; 8(1): e1002490.

Fallon MB, Krowka MJ, Brown RS, Trotter JF, Zacks S, Roberts KE, et al. Impact of hepatopulmonary syndrome on quality of life and survival in liver transplant candidates. Gastroenterology. 2008; 135(4): 1168-75.

Ferreira PP, Camara EJ, Paula RL, Zollinger CC, Cavalcanti AR, Bittencourt PL. Prevalence of hepatopulmonary syndrome in patients with decompensated chronic liver disease and its impact on short-term survival. Arq Gastroenterol. 2008; 45(1): 34-7.

Ferreira RCS, Domingues AL, Markman Filho B, Veras FH, Batista LJ, Albuquerque Filho ES. Hepatopulmonary syndrome in patients with Schistosoma mansoni periportal fibrosis. Acta Trop. 2009; 111(2): 119-24.

Gryseels B. Schistosomiasis. Infect Dis Clin North Am. 2012; 26(2): 383-97.

Kamath PS, Wiesner RH, Malinchoc M, Kremers W, Therneau TM, Kosberg CL, et al. A model to predict survival in patients with end-stage liver disease. Hepatology. 2001; 33(2): 464-70.

Kaymakoglu S, Kahraman T, Kudat H, Demir K, Cakaloglu Y, Adalet $\mathrm{I}$, et al. Hepatopulmonary syndrome in noncirrhotic portal hypertensive patients. Dig Dis Sci. 2003; 48(3): 556-60.

Lambertucci JR. Revisiting the concept of hepatosplenic schistosomiasis and its challenges using traditional and new tools. Rev Soc Bras Med Trop. 2014; 47(2): 130-6.

Lapa M, Dias B, Jardim C, Fernandes CJ, Dourado PM, Figueiredo $\mathrm{M}$, et al. Cardiopulmonary manifestations of hepatosplenic schistosomiasis. Circulation. 2009; 119(11): 1518-23.

Machicao VI, Fallon MB. Hepatopulmonary syndrome. Semin Respir Crit Care Med. 2012; 33(1): 11-6.

Martínez GP, Barberà JA, Visa J, Rimola A, Paré JC, Roca J, et al. Hepatopulmonary syndrome in candidates for liver transplantation. J Hepatol. 2001; 34(5): 651-7.

Merkel C, Montagnese S. Should we routinely measure portal pressure in patients with cirrhosis, using hepatic venous pressure gradient (HVPG) as guidance for prophylaxis and treatment of bleeding and re-bleeding? Yes! Eur J Intern Med. 2011; 22(1): 1-4.

Pereira CA, Sato T, Rodrigues SC. New reference values for forced spirometry in white adults in Brazil. J Bras Pneumol. 2007; 33(4): 397-406.

Richter J, Domingues ALC, Barata CH, Prata AR, Lambertucci JR. Report of the second satellite symposium on ultrasound in schistosomiasis. Mem Inst Oswaldo Cruz. 2001; 96(Suppl.):151-6.

Rodríguez-Roisin R, Krowka MJ, Hervé P, Fallon MB, Committee ETFP-HVDPS. Pulmonary-Hepatic vascular Disorders (PHD). Eur Respir J. 2004; 24(5): 861-80.

Simonneau G, Gatzoulis MA, Adatia I, Celermajer D, Denton C, Ghofrani A, et al. Updated clinical classification of pulmonary hypertension. J Am Coll Cardiol. 2013; 62(Suppl. 25): D34-41.

Van-Lume DS, Albuquerque MF, Souza AI, Domingues AL, Lopes EP, Morais CN, et al. Association between Schistosomiasis mansoni and hepatitis C: systematic review. Rev Saude Publica. 2013; 47(2): 414-24.

Vedrinne JM, Duperret S, Bizollon T, Magnin C, Motin J, Trepo C, et al. Comparison of transesophageal and transthoracic contrast echocardiography for detection of an intrapulmonary shunt in liver disease. Chest. 1997; 111(5): 1236-40. 